\title{
Prevalence and epidemiological factors associated with hypertension among post-menopausal women in an urban area of central India
}

\author{
Prashant Shridhar Bagdey, Juveria Ahfaz Ansari, Rajan Kumar Barnwal* \\ Department of Community Medicine, Government Medical College, Nagpur, India
}

\section{A R T I C L E I N F O}

\section{Keywords:}

Hypertension

Postmenopausal Women

Risk factors

Non-communicable disease

\begin{abstract}
A B S T R A C T
Background: Hypertension is one of the leading cause of global burden of disease. Blood pressure is typically lower in premenopausal women than in their male counterparts. But women loose this advantage after menopause.

Objectives: Objectives of study were to know the prevalence of hypertension among postmenopausal women and to study some of its epidemiological factors.

Methodology: It was a community based cross-sectional study with a sample size of 100 postmenopausal women residing in Kamptee, an urban satellite township of Nagpur district in central India conducted for a period of two months. A written informed consent was taken and a study questionnaire was administered to the participants. Data regarding demographic characteristics, alcohol and tobacco consumption, dietary habits, physical activity, psychological stress and family history was obtained. Physical examination such as waist circumference, hip circumference, weight, height, blood pressure and pulse rate was recorded. Blood pressure was recorded using mercury sphygmomanometer and weight was recorded using standardised electronic weighing machine.

Results: The prevalence of hypertension in postmenopausal women in the urban area was found to be $33 \%$. The prevalence of isolated systolic hypertension was $30 \%$ and that of isolated diastolic blood pressure was $44 \%$. There was significant difference in positive family history of hypertension and body mass index (BMI) between hypertensive and non-hypertensive women.

Conclusion: The prevalence of hypertension (33\%) among postmenopausal women in Kamptee town was high. There was large burden of risk factors among the study population.
\end{abstract}

\section{Introduction}

Hypertension is one of the leading cause of global burden of disease, posing a major public challenge to population in socio-economic and epidemiological transition. This problem is of special concern for developing countries, where studies have projected an increase by $80 \%$ in the number of hypertensives by the year $2025^{1}$.

In the INTERHEART and INTERSTROKE study, hypertension accounts for $17.9 \%$ and $34.6 \%$ population attributable risk for coronary artery diseases and stroke respectively ${ }^{2-3}$. It is one of the major cause of cardiovascular mortality, which is estimated to be 1.5 million deaths per year in India ${ }^{4}$.

The Seventh Report of the Joint National Committee on Prevention, Detection, Evaluation, and Treatment of High Blood Pressure (JNC7) defines hypertension as systolic blood pressure (SBP) of $140 \mathrm{mmHg}$ and above and/or diastolic blood pressure (DBP) of $90 \mathrm{mmHg}$ and above ${ }^{5}$. Both systolic and diastolic blood pressure increase with advancing age. It is seen that blood pressure is typically lower in premenopausal women than in their male counterparts. However, after menopause, the prevalence of hypertension in women is higher than it is in men of same age group, which in turn leads to increased morbidity and mortality in postmenopausal women ${ }^{6}$.

In view of population aging throughout the world, identification of possible risk factors and prevention of hypertension in postmenopausal women are important. An association of hypertension with the menopause and related risk factors need to be given due attention to avoid increased burden of hypertension and related cardiovascular diseases (CVDs) among women. The present cross-sectional study is conceptualized to provide the data on the prevalence of hypertension in postmenopausal women and association of some epidemiological factors with the same.

\section{Literature review}

There are some studies done in India and abroad which shows high prevalence of hypertension and its risk factors in postmenopausal

\footnotetext{
* Corresponding author.

E-mail addresses: dr.prashantbagdey@yahoo.com (P.S. Bagdey), ansarijuveria.9r@gmail.com (J.A. Ansari), rajan_barnwal87@yahoo.in (R.K. Barnwal).
} 
women:

A community based cross-sectional study on hypertension and its risk factors was conducted in an urbanized village of Delhi. The prevalence of hypertension in postmenopausal women was found to be $39.6 \%{ }^{8}$. Obesity, smoking, family history and physical activity were significantly higher among hypertensives as compared to non-hypertensives.

A study in North Delhi involved a survey of 245 females of age range 20 to 65 years. Data regarding demographic characteristics, anthropometric measurements, lifestyle and blood pressure pattern was collected. According to the systolic blood pressure $27.2 \%$ of postmenopausal women were found to be hypertensive. Similarly, $41.1 \%$ of postmenopausal women were found to be hypertensive as per the diastolic blood pressure ${ }^{7}$. BMI and waist circumference showed statistically significant $(\mathrm{p}<0.001)$ higher values among hypertensive postmenopausal women as compared to their normal counterparts. The females taking non-vegetarian diet were 3 times more likely to develop hypertension. Also educational level of females was found to be significantly correlated with the chances of them being hypertensive.

A descriptive study conducted among 350 perimenopausal and postmenopausal women at Urban Health Centre, Bandra, Mumbai revealed that the prevalence of hypertension was more among postmenopausal women $(36.76 \%)$ as compared to perimenopausal women $(3.03 \%)^{9}$. Statistically, it was found to be significant.

In the Chennai Urban Rural Epidemiology Study, it was found that the prevalence of isolated systolic hypertension increased at a lower pace until the age of 50, after which, it increased dramatically yielding a prevalence of $11.9 \%$ (men: $10.9 \%$, women: 13.1 ) at the age group of 50-59 years and $25.2 \%$ (men: $21.4 \%$, women: $30.2 \%$ ) at the age of 60 years and above ${ }^{10}$.

An epidemiological study of hypertension in a rural household community shows $22.6 \%$ adult males and $27.4 \%$ adult females are suffering from hypertension. Greater prevalence was observed in unemployed and unskilled category of occupation. The prevalence of hypertension was higher $33.3 \%$ among those who were in the habit of chewing tobacco for more than 5 years as compared to $31.6 \%$ who had this habit for less than 5 years. The lower prevalence rate of hypertension among non-tobacco chewers was $23.5 \%$. Among hypertensives, $29.1 \%$ were obese, $13.7 \%$ were class 1 and $5.8 \%$ were class 2 obese. These differences were highly significant $(\mathrm{p}<0.001)$. The prevalence was also higher among those who were taken oral contraceptive pills for more than 3 years $(66.6 \%)$ and it was $46.3 \%$ among those taking the oral contraceptive pills for less than 3 years. Similarly, environmental stress and anxiety were found to have statistically significant higher risk for hypertension ${ }^{11}$.

The aims of this study were 1) To know the prevalence of hypertension among postmenopausal women in an urban area of central India. 2) To study some epidemiological factors associated with hypertension in postmenopausal women.

\section{Material and methods}

The present cross-sectional study was conducted in Kamptee, an urban satellite township of Nagpur district in central India from August 1, 2016 to September 30, 2016. A total of 100 postmenopausal women were included in the study. We excluded severely ill or bed-ridden patients. For data collection, a house-to-house survey was carried out in a ward of Kamptee town. The ward was selected by lottery method. The first house in the ward was selected from the last digit of a five rupees currency note then every tenth house was visited.

Postmenopausal women were identified by the criteria of cessation of menstrual period for more than 12 consecutive months ${ }^{12}$. After written informed consent, a study questionnaire was administered to the participants. Data regarding demographic characteristics, tobacco and alcohol consumption, dietary habits, physical activity, psychological stress, use of oral contraceptive pills and family history was obtained. Socioeconomic status was calculated using Modified Kuppuswamy's Socioeconomic Scale. This scale takes account of education, occupation, and income level of an individual with a different score for each of these three parameters summing up to total scores to classify the study groups as upper, upper middle, and lower socioeconomic status $^{13}$. The food habits were broadly classified as vegetarian and nonvegetarian. Information regarding the frequency of meat consumption, daily salt consumption, amount of carbonated soft drinks and servings of fast food consumed in last 7 days was collected. Global physical activity questionnaire (GPAQ) Version 2 was used to assess physical activity $^{14}$. The Perceived Stress Scale (PSS) was applied to assess the stress among the subjects ${ }^{15}$.

Blood pressure for all the participants was measured by the auscultatory method in sitting position using a mercury sphygmomanometer, in left arm, 2 times, 5 minutes apart and an average of two readings was taken. The primary investigator had been trained in the standardized technique by skilled medical practitioner. In case where the two readings differed by over $10 \mathrm{~mm}$ of $\mathrm{Hg}$, a third reading was obtained, and the three measurements were averaged. Normal blood pressure was taken as less than $120 \mathrm{mmHg}$-systolic and less than 80 mmHg-diastolic. Participants with the blood pressure values of 120 to $139 \mathrm{mmHg}$ (systolic) or 80 to $89 \mathrm{mmHg}$ (diastolic) were classified under pre-hypertension category. Stage-I hypertension was taken as 140 to $159 \mathrm{mmHg}$-systolic or 90 to $99 \mathrm{mmHg}$-diastolic, whereas StageII hypertension was taken as blood pressure of more than 160 mmHg-systolic or more than $100 \mathrm{mmHg}$-diastolic, as per US Seventh Joint National Committee on Detection, Evaluation and Treatment of Hypertension (JNC VII) criteria ${ }^{5}$. Pulse rate was counted manually in the radial artery for complete one minute.

Height was measured without slippers to the nearest $0.1 \mathrm{~cm}$ and weight was measured using digital weighing machine. Body mass index was calculated. BMI $\geq 23 \mathrm{~kg} / \mathrm{m}^{2}$ was taken as overweight ${ }^{16}$. Waist circumference was measured in standing position mid-way between lowest rib and iliac crest. Hip circumference was measured at the level of maximum posterior extension of buttocks, over light clothing. Waist Hip Ratio was calculated using waist and hip circumference. All measurements were taken by primary investigator according to standard techniques.

\subsection{Data Analysis}

The data was analysed using Epi Info 7 Version 22.0 statistical software. Mean and standard deviation were calculated. Tests of significance, chi- square test was applied to find out the association. The study was approved by the Institutional Ethics Committee, Government Medical College, Nagpur.

\section{Results}

\subsection{Demographic Characteristics}

100 postmenopausal women individuals of Kamptee participated in the study. The age of the study population ranged from 40-85 years with the mean age of $59.5 \pm 9.8$ years. Majority of respondents were aged between $50-64$ years of age (61\%).

Majority of women were married (62\%), Muslim by religion (72\%), literate (93\%) and unemployed (67\%). Out of 100, 41 study subjects belonged to lower middle followed by $32 \%$ belonged to upper lower socio-economic status. Out of total 100 postmenopausal women, 67 unemployed study subjects were housewives and stayed at home [Table 1].

\subsection{Prevalence of Hypertension}

The prevalence of hypertension in postmenopausal women was $33 \%$ while $48 \%$ were found to be pre-hypertensive [Table 2]. The mean 
Table 1

Socio-Demographic Profile of Postmenopausal Women.

\begin{tabular}{|c|c|c|}
\hline SOCIO-DEMOGRAPHIC FACTOR & $\begin{array}{l}\text { NUMBER OF WOMEN } \\
(\mathrm{n}=100)\end{array}$ & PERCENT \\
\hline \multicolumn{3}{|l|}{ RELIGION } \\
\hline HINDU & 6 & $6.00 \%$ \\
\hline MUSLIM & 72 & $72.00 \%$ \\
\hline BUDDHIST & 21 & $21.00 \%$ \\
\hline JAIN & 1 & $1.00 \%$ \\
\hline \multicolumn{3}{|l|}{ MARITAL STATUS } \\
\hline SINGLE & 3 & $3.00 \%$ \\
\hline MARRIED & 62 & $62.00 \%$ \\
\hline WIDOWED & 35 & $35.00 \%$ \\
\hline \multicolumn{3}{|l|}{ EDUCATION } \\
\hline PROFESSION OR HONOURS & 1 & $1.00 \%$ \\
\hline GRADUATE OR POST-GRADUATE & 12 & $12.00 \%$ \\
\hline $\begin{array}{l}\text { INTERMEDIATE OR POST HIGH SCHOOL } \\
\text { DIPLOMA }\end{array}$ & 9 & $9.00 \%$ \\
\hline HIGH SCHOOL CERTIFICATE & 12 & $12.00 \%$ \\
\hline MIDDLE SCHOOL CERTIFICATE & 21 & $21.00 \%$ \\
\hline PRIMARY SCHOOL CERTIFICATE & 38 & $38.00 \%$ \\
\hline ILLITERATE & 7 & $7.00 \%$ \\
\hline \multicolumn{3}{|l|}{ OCCUPATION } \\
\hline SEMI-PROFESSION & 7 & $7.00 \%$ \\
\hline SHOP-OWNER & 1 & $1.00 \%$ \\
\hline SKILLED WORKER & 17 & $17.00 \%$ \\
\hline SEMI-SKILLED WORKER & 2 & $2.00 \%$ \\
\hline UNSKILLED WORKER & 6 & $6.00 \%$ \\
\hline UNEMPLOYED & 67 & $67.00 \%$ \\
\hline \multicolumn{3}{|l|}{ SOCIO-ECONOMIC STATUS } \\
\hline UPPER & 1 & $1.00 \%$ \\
\hline UPPER MIDDLE & 26 & $26.00 \%$ \\
\hline LOWER MIDDLE & 41 & $41.00 \%$ \\
\hline UPPER LOWER & 32 & $32.00 \%$ \\
\hline TOTAL & 100 & $100.00 \%$ \\
\hline
\end{tabular}

Table 2

Prevalence of Hypertension in Postmenopausal Women.

\begin{tabular}{llll}
\hline CATEGORY & $\begin{array}{l}\text { BLOOD } \\
\text { PRESSURE(SBP/ } \\
\text { DBP) }\end{array}$ & $\begin{array}{l}\text { NUMBER OF } \\
\text { WOMEN } \\
(\mathrm{n}=100)\end{array}$ & PERCENTAGE \\
\hline NORMAL & $<120 /<80$ & 19 & $19.00 \%$ \\
PRE HYPERTENSION & $120-139 / 80-89$ & 48 & $48.00 \%$ \\
HYPERTENSION STAGE & $140-159 / 90-99$ & 15 & $15.00 \%$ \\
$\quad \begin{array}{l}1 \\
\text { HYPERTENSION }\end{array} \quad 160 / \geq 100$ & 18 & $18.00 \%$ \\
$\quad$ STAGE 2 & TOTAL & 100 & $100.00 \%$ \\
\hline
\end{tabular}

Table 3

Distribution of Study Population as per Systolic and Diastolic Blood Pressure.

\begin{tabular}{lcc}
\hline & NUMBER OF WOMEN (n = 100) & PERCENTAGE \\
\hline SYSTOLIC BLOOD PRESSURE & & \\
NORMAL & 31 & $31.00 \%$ \\
PRE-HYPERTENSION & 39 & $39.00 \%$ \\
HYPERTENSION STAGE 1 & 21 & $21.00 \%$ \\
HYPERTENSION STAGE 2 & 9 & $9.00 \%$ \\
DIASTOLIC BLOOD PRESSURE & & \\
NORMAL & 26 & $26.00 \%$ \\
PRE-HYPERTENSION & 30 & $30.00 \%$ \\
HYPERTENSION STAGE 1 & 25 & $25.00 \%$ \\
HYPERTENSION STAGE 2 & 19 & $19.00 \%$ \\
TOTAL & $\mathbf{1 0 0}$ & $\mathbf{1 0 0 . 0 0 \%}$ \\
\hline
\end{tabular}

systolic blood pressure was $128.5 \pm 23.5$ with range of $80-190$ and mean diastolic pressure was $88.9 \pm 15.6$ with range of $60-130$. As per systolic blood pressure, $30 \%$ women were found to be hypertensive.
Similarly, according to diastolic blood pressure, $44 \%$ were found to be hypertensive [Table 3].

\subsection{Hypertension and Risk factors}

Table 4 displays the risk factors of hypertension. 96\% women were at risk of hypertension as the reported salt intake was equal or more than 5 grams/day. 64\% reported some kind of stress either moderate or severe. Family history of hypertension was found in $48 \%$ of women. This risk factor is significantly higher among hypertensive as compared to non-hypertensive ( $\mathrm{p}<0.05$ ). 39\% women gave history of tobacco chewing. $19 \%$ women were currently exposed to homemade smoke. Mild physical activity was reported in $47 \%$ women as compared to moderate physical activity reported by $53 \%$ women. $93 \%$ women were taking mixed type of diet that is both vegetarian diet and meat. $68 \%$ and $54 \%$ postmenopausal women had waist circumference more than or equal to $80 \mathrm{~cm}$ and waist hip ratio more than or equal to 0.85 , respectively. $16 \%$ of women were obese BMI more than or equal to $23^{16}$. There is significant difference in BMI between hypertensive and nonhypertensive women $(\mathrm{p}<0.05)$.

We also considered alcohol consumption, carbonated soft drink, fast food and oral contraceptive pills as one of the risk factors but the data obtained was practically negligible.

\section{Discussion}

The prevalence of hypertension in postmenopausal women in the urban area was found to be $33 \%$. Moreover, the prevalence of isolated systolic hypertension was $30 \%$ and that of isolated diastolic blood pressure was $44 \%$. Our findings were comparable to that reported by the studies in other parts of the country ${ }^{7,8,9,17}$. It was found that $96 \%$ women were at high risk because of salt intake ( $\geq 5$ grams per day). Mean salt intake of the study population was $12.2 \pm 1.7$, ranging from 3.3-20 grams per day. The results showed that $48 \%$ women had family history of hypertension. Hypertensive women had significantly higher percentage for positive family history than rest of the study population. Among the women who ever used smokeless tobacco product (39\%), $31 \%$ were current chewers and $8 \%$ were past chewers. The prevalence of current tobacco chewing in this study was found to be higher than the prevalence reported in another study on hypertension in postmenopausal women ${ }^{8} .47 \%$ study subjects were reported to have mild physical activity. The prevalence of mild physical activity was higher as compared to data obtained from other similar studies ${ }^{18}$. Also, $30 \%$ women were spending more than $5 \mathrm{hrs}$. sitting at home or work place. Waist hip ratio was found to be $\geq 0.85$ in $54 \%$ of study population. $16 \%$ women had body mass index $\geq 23 \mathrm{~kg} / \mathrm{m}^{2}$. Hypertensive women had significantly higher value of BMI than non-hypertensive women.

Strength of this study is the fact that it was a community based study.

\subsection{Limitations to the Study}

This study was limited to a single urban area in central India. The findings may not be generalized to similar populations in other areas of India. Other limitation of this study was its small sample size.

\section{Conclusion}

It was concluded from the study that the prevalence of hypertension (33\%) among postmenopausal women in Kamptee town was high. Also there is a large burden of risk factor among the study population. In view of the current scenario we give the following recommendations.

\section{Recommendation}

The women having positive family history should be screened 
Table 4

Risk Factors of Hypertension among Postmenopausal Women

\begin{tabular}{|c|c|c|c|c|c|c|c|c|}
\hline \multirow[t]{2}{*}{ RISK FACTORS } & & \multicolumn{5}{|l|}{ BLOOD PRESSURE } & \multirow[t]{2}{*}{ df } & \multirow[t]{2}{*}{$\mathrm{p}$ value } \\
\hline & & Normal $(\mathrm{n}=19)$ & Pre hypertensive $(\mathrm{n}=48$ ) & Stage $1(n=15)$ & Stage $2(\mathrm{n}=18)$ & Total & & \\
\hline \multirow[t]{2}{*}{ Salt intake } & $<5$ g/day & 0 & 2 & 0 & 2 & 4 & 3 & 0.285 \\
\hline & $\geq 5$ g/day & 19 & 46 & 15 & 16 & 96 & 3 & \\
\hline \multirow[t]{2}{*}{ Stress } & Absent & 8 & 15 & 6 & 7 & 36 & 3 & 0.814 \\
\hline & Present & 11 & 33 & 9 & 11 & 64 & 3 & \\
\hline \multirow[t]{2}{*}{ Family history } & Absent & 10 & 31 & 8 & 3 & 52 & 3 & 0.007 \\
\hline & Present & 9 & 17 & 7 & 15 & 48 & 3 & \\
\hline \multirow[t]{2}{*}{ Tobacco chewing } & No & 15 & 26 & 9 & 11 & 61 & 3 & 0.318 \\
\hline & Yes & 4 & 22 & 6 & 7 & 39 & 3 & \\
\hline \multirow{2}{*}{ Currently exposed to homemade smoke } & No & 16 & 40 & 10 & 15 & 81 & 3 & 0.501 \\
\hline & Yes & 3 & 8 & 5 & 3 & 19 & 3 & \\
\hline \multirow[t]{2}{*}{ Physical activity } & Mild & 6 & 26 & 9 & 6 & 47 & 3 & 0.160 \\
\hline & Moderate & 13 & 22 & 6 & 12 & 53 & 3 & \\
\hline \multirow[t]{2}{*}{ Diet } & Pure vegetarian & 1 & 5 & 0 & 1 & 7 & 3 & 0.545 \\
\hline & Mixed & 18 & 43 & 15 & 17 & 93 & 3 & \\
\hline \multirow[t]{2}{*}{ Waist circumference } & $<80 \mathrm{~cm}$ & 8 & 16 & 4 & 4 & 32 & 3 & 0.590 \\
\hline & $\geq 80 \mathrm{~cm}$ & 11 & 32 & 11 & 14 & 68 & 3 & \\
\hline \multirow[t]{2}{*}{ Waist hip ratio } & $<0.85$ & 7 & 22 & 7 & 10 & 46 & 3 & 0.728 \\
\hline & $\geq 0.85$ & 12 & 26 & 8 & 8 & 54 & 3 & \\
\hline \multirow[t]{2}{*}{ Body mass index } & $<23 \mathrm{Kg} / \mathrm{m}^{2}$ & 19 & 42 & 12 & 11 & 84 & 3 & 0.01 \\
\hline & $\geq 23 \mathrm{Kg} / \mathrm{m}^{2}$ & 0 & 6 & 3 & 7 & 16 & 3 & \\
\hline
\end{tabular}

periodically and the women suffering from obesity should receive proper treatment. Counselling of the population on lifestyle modification and its role in controlling hypertension should also be emphasized to avoid further burden of both the disease and the risk factors. Similar studies should be conducted in postmenopausal women from different parts of the country.

\section{Conflicting of interest}

Nil.

\section{Funding}

Nil.

\section{Presentation at a meeting}

Nil.

\section{Acknowledgement}

We are thankful to all the study participants who consented to be part of this study.

\section{References}

1. Kearney PM, Whelton M, Reynolds K, Muntner P, Whelton PK, He J. Global burden of hypertension: analysis of worldwide data. Lancet. 2005;365(9455):217-223 PubMed PMID: 15652604. [PubMed]

2. Yusuf S, Hawken S, Ônpuu S, et al. Effect of potentially modifiable risk factors associated with myocardial infarction in 52 countries (the INTERHEART study): casecontrol study. Lancet. 2004;364:937-952.
3. O'Donnell MJ, Xavier D, Liu L, et al. Risk factors for ischaemic and intracerebral haemorrhagic stroke in 22 countries (the INTERSTROKE study): a case-control study. Lancet. 2010;376:112-123.

4. Gaziano T, Reddy KS, Paccaud F, Horton S, Chaturvedi V. Cardiovascular disease. In: Jamison DT, Mosely WH, eds. Disease Control Priorities in Developing World. Oxford: Oxford University Press; 2006:645-662.

5. Chobanian AV, Bakris GL, Black HR, et al. The seventh report of the joint national committee on prevention, detection, evaluation, and treatment of high blood pressure: the JNC 7 report. JAMA. 2003;289:2560-2572.

6. Lima R, Wofford M, Reckelhoff JF. Hypertension in Postmenopausal Women. Curr Hypertens Rep. 2012;14(3):254-260.

7. Tyagi R, Dhall M, Kapoor S. Bio-Social Predictors of Hypertension Among Premenopausal and Postmenopausal Women. SAGE OPEN; 2015:1-12.

8. Gupta N, Vibha, Khandekar J, Jain A, Gupta S. Hypertension and its risk factors among postmenopausal women in Delhi. Indian J Community Health 2014;26(04):412-416.

9. Deotale M, Ranganathan U, Mankeshwar R, Akarte S. Study of Cardiovascular Risk Factors in Perimenopausal and Postmenopausal Women in an Urban Community. Int J Curr Med Appl Sci. 2014;4(1):13-17.

10. Mohan V, Deepa M, Farooq S, Datta M, Deepa R. Prevalence, Awareness and Control of Hypertension in Chennai-The Chennai Urban Rural Epidemiology Study(CURES52). JAPI. 2007:55:326-332.

11. Kannan L, Satyamoorthy T. An epidemiological study of hypertension in a rural household community. Sri Ramchandra J Med. 2009;2(2):9-13.

12. World Health Organisation. Research on the Menopause in the 1990: report of a WHO Scientific Group Geneva: WHO; 1996 WHO Technical Report Series, No. 866.

13. Sharma R. Kuppuswamy's socioeconomic status scale - revisionfor 2011 and formula for real-time updating. Indian J Pediatr. 2012;79(7):961-962.

14. World Health Organisation. WHO STEPS Surveilliance Manual: the WHO STEP wise approach for chronic diseases risk factorssurveilliance. Geneva: WHO; 2005.

15. Cohen S, Kamarick T, Mermelstein R. A global measure of perceived stress. J Health Soc Behav. 1983;24(4):285-396.

16. World Health Organisation Western Pacific Region. The Asia-Pacific Perspective: Redefining Obesity and its Treatment. 2000; 2000 IASO February.

17. Kaur M. Prevalence and association of hypertension and bone mineral density among postmenopausal women of North India. Health Sci Res. 2015;2(6):50-54.

18. Ogwumike O, Adeniyi AF, Dosa BT, Sanya AO, Awolola KO. Physical activity and pattern of blood pressure in postmenopausal women with hypertension in Nigeria. Ethiop J Health Sci. 2014;24(2):153-160. 